\title{
Factors influencing growth hormone therapy effect during the prepubertal period in small for gestational age children without catch-up growth
}

\author{
Chang Dae Kum ${ }^{1}$, \\ Jung Gi Rho', \\ Hong Kyu Park', \\ Hae Sang Lee', \\ Jin Soon Hwang ${ }^{1}$
}

'Department of Pediatrics, Ajou University School of Medicine, Suwon, Korea

${ }^{2}$ Department of Pediatrics, Gyeongsang National University Changwon Hospital, Changwon, Korea
Received: 8 May, 2020

Revised: 14 August, 2020

Accepted: 23 December, 2020

Address for correspondence: Jin Soon Hwang

Department of Pediatrics, Ajou University School of Medicine, 164 Worldcup-ro, Yeongtong-gu, Suwon 16499, Korea

Email: pedhwang@aumc.ac.kr https://orcid.org/0000-0002-26663801
Purpose: Because small for gestational age (SGA) children who fail to experience catch-up growth have an increased risk of short stature in adulthood, growth hormone $(\mathrm{GH})$ treatment is recommended for effective growth. In this study, we evaluated the effect of GH treatment during the prepubertal period and analyzed for correlation between GH treatment response and clinical factors in SGA children. Methods: A retrospective, single-center study was conducted from 2014 to 2020. A total of 34 prepubertal children of short stature up to 4 years of age and born as SGA were enrolled. We recorded clinical data including birth data, age, weight, height, bone age (BA), and insulin-like growth factor 1 (IGF-1) levels.

Results: The mean gestational age and birth weight were $37.50 \pm 2.51$ weeks and $2,200.00 \pm 546.79 \mathrm{~g}$. At the start of GH treatment, the mean chronological age and BA were $5.54 \pm 1.73$ years and $4.52 \pm 1.85$ years, respectively. The height standard deviation score (SDS) $(-2.47 \pm 0.45)$ and IGF-1 SDS $(0.16 \pm 1.57)$ were calculated. Height velocity was $9.43 \pm 1.40 \mathrm{~cm}$ during the first GH treatment year and $7.63 \pm 1.16$ $\mathrm{cm}$ during the second year $(P<0.05)$. The treatment growth response was positively correlated with young age $(P=0.047)$ and lower $\mathrm{BA}(P=0.049)$ at the start of treatment. In multiple regression analysis, IGF-1 SDS change had a significantly positive association with $\mathrm{GH}$ treatment response $(P=0.045)$.

Conclusion: GH treatment is effective for short stature SGA children who do not experience catch-up growth. Early initiation of GH treatment improved growth outcomes. As IGF-1 SDS is positively correlated with height SDS, IGF-1 monitoring is important during GH treatment of SGA prepubertal children.

Keywords: Small for gestational age, Growth Hormone, Short stature, Child

\section{Highlights}

GH treatment is effective for short stature SGA prepubertal children. Early initiation of GH treatment improved growth outcomes. IGF-1 monitoring is important during GH treatment of SGA prepubertal children.

\section{Introduction}

The most common definition of small for gestational age (SGA) is a birth weight and/or length at least 2 standard deviation score (SDS) below the mean for sex and gestational age. ${ }^{1)}$ SGA is related to the risk of both long- and short-term metabolic and medical consequences. In particular, SGA children are at a higher risk of short stature in later life than those children of appropriate size for gestational age, with SGA accounting for approximately $20 \%$ of all short stature cases. ${ }^{2}$ Most children born SGA (85\%-90\%) exhibit catch-up growth defined 
as growth velocity above the normal range, normalizing their height at 2-4 years of age. ${ }^{3)}$

Around $10 \%$ of SGA children do not undergo catchup growth and remain short in stature during adult life. ${ }^{2)}$ The reason for this is not yet completely understood. One hypothesis suggests that failure of catch-up growth is caused by disturbances in the growth hormone $(\mathrm{GH})$ axis., ${ }^{4,5}$ During infancy, spontaneous GH secretion and circulating insulin-like growth factor 1 (IGF-1) levels have been indicated to be either decreased or increased in SGA infants. These defects in the GHIGF axis result in poor catch-up growth. ${ }^{6,7)}$ Another study found a significant positive correlation between birth weight, birth length SDS, and spontaneous catch-up growth at 2 years in SGA children. ${ }^{8)}$

Many previous studies have determined that final adult height of SGA children given GH treatment was significantly higher compared to that of untreated SGA children." GH therapy is an approved treatment for increasing final adult height in short stature SGA children who do not undergo spontaneous catch-up growth and achieve a normal adult height. ${ }^{10)}$ The U.S. Food and Drug Administration and the European Agency for the Evaluation of Medical Products approved the use of GH treatment in 2003 and GH treatment for short children with SGA has been licensed for more than 10 years. ${ }^{11)}$ The aims of GH treatment are to induce safe catch-up growth and maintain normal height gain during childhood to attain a normal target height range in adulthood. ${ }^{12-14)}$

Since August 2014, GH treatment has been covered by Korean national medical insurance for short stature children born SGA without undergoing catch-up growth by 4 years of age. After Korean medical insurance approval, GH therapy for SGA children diagnosed with short stature has become much more frequent. Although many studies have found that $\mathrm{GH}$ treatment is an effective therapy in individuals with SGA who do not undergo catch-up growth, limited research has been conducted in Korean SGA children. In this study, we evaluated the growth effect of GH therapy for 2 years in SGA children without catchup growth as approved by Korean medical insurance after 4 years of age. Moreover, we analyzed the predicting factors of GH treatment response for a 2-year follow-up period in Korean SGA children.

\section{Materials and methods}

\section{Subjects}

We retrospectively reviewed and recorded short stature SGA patients who were treated with subcutaneous GH between August 2014 and June 2020 at the Ajou University Hospital, Suwon, South Korea. A total 34 SGA patients who were given $\mathrm{GH}$ for a 2 -year period were enrolled.

Inclusion criteria: SGA defined by birth weight and/or length at least 2 SDS below the mean for sex and gestational age below the standard reference ${ }^{1)}$; below the 3 rd percentile of height with regard to sex and age by 4 years of age ${ }^{15)}$; patients who were at the prepubertal stage at the start of treatment and during 2-year treatment period.

Exclusion criteria: Patients who did not meet the inclusion criteria; ruling out other significant metabolic, chronic, chromosomal, and endocrinology diseases affecting appropriate growth.

\section{Methods}

We collected patient records including birth weight and gestational age. Measurements, including height, weight, body mass index (BMI), IGF-1 levels and bone age (BA) were checked every 6 months. BA was evaluated using the Greulich-Pyle method. ${ }^{16)}$ The measurement of height was conducted using a Harpenden stadiometer (Holtain Ltd., Crymych, UK). BMI was calculated as body mass divided by height squared $(\mathrm{kg} /$ $\mathrm{m}^{2}$ ). IGF-1 levels were measured by radioimmunoassay using polyclonal antibodies. The calculated IGF-1 SDS was based on the least mean-squares method using the specific reference for the Korean population. ${ }^{17)}$ To calculate SDS value of height, weight, and BMI, the following equation was used referencing the Box-Cox transformation (L), median (M), and coefficient of variation (S) values from growth standards for Korean children and adolescents. ${ }^{18)} \mathrm{SDS}=[$ power (measured value $/ \mathrm{M}, \mathrm{L}$ )- 1$] / \mathrm{L} \times \mathrm{S}$.

The onset of puberty was defined as a breast development stage II according to Tanner for girls and testicular volume $>4$ $\mathrm{mL}$ for boys. ${ }^{19)}$ The initial dose of GH treatment in all patients was $0.33 \mathrm{mg} / \mathrm{kg} / \mathrm{wk}$. The GH dose was divided and administered 6 times a week and doses were subcutaneously injected. The GH dose was adjusted based on measured weight every 3 months during hospital visits. In addition, we regulated the $\mathrm{GH}$ dose for SGA patients considering growth velocity.

\section{Statistical methods}

To describe patient baseline characteristics, quantitative variables are presented as measurements and calculation data are presented as the mean \pm standard deviation (SD). Changes in height, weight, and BMI were examined using a paired $t$-test or Wilcoxon signed-rank test. The normality assumption was checked via Kolmogorov-Smirnov or Shapiro-Wilk tests. The responses of each variable on growth velocity were examined using correlation analysis and multiple linear regression analysis.

All of the statistical evaluations were analyzed using IBM SPSS statistics ver. 25.0 (IBM Corp., Armonk, NY, USA). A significant statistical $P$-value was regarded as less than 0.05 .

\section{Results}

\section{Baseline characteristics}

Table 1 reports the clinical baseline characteristics of short stature SGA children who were administered GH treatment. 
In the study, 34 children participated, of which 59\% were boys. The mean gestational age was $37.50 \pm 2.51$ weeks and the mean birth weight was $2,200.00 \pm 546.79 \mathrm{~g}$. The number of premature infants, defined as gestational age under 37 weeks, was 8 out of 34 (24\%) SGA children. At the beginning of GH therapy, the mean chronological age $(\mathrm{CA})$ was $5.54 \pm 1.73$ years and the mean BA was $4.52 \pm 1.85$ years. Additionally, the calculated height SDS and IGF-1 SDS were $-2.47 \pm 0.45$ and $0.16 \pm 1.57$, respectively. The mean GH dose was $0.27 \mathrm{mg} / \mathrm{kg} / \mathrm{wk}$ for the 2 -year period.

Table 1. Clinical baseline characteristics of growth hormone treatment in SGA children

\begin{tabular}{lc}
\hline Characteristic & Value \\
\hline At birth & \\
Sex, male : female & $20: 14$ \\
Gestational age (wk) & $37.50 \pm 2.51$ \\
Birth weight (g) & $2,200.00 \pm 546.79$ \\
At start of GH & \\
Age (yr) & $5.54 \pm 1.73$ \\
BA (yr) & $4.52 \pm 1.85$ \\
BA/CA & $0.81 \pm 0.11$ \\
Height (cm), (SDS) & $-2.47 \pm 0.45$ \\
Weight (kg), (SDS) & $-2.73 \pm 1.22$ \\
BMI (kg/m ${ }^{2}$, (SDS) & $-1.29 \pm 1.32$ \\
IGF-1 (ng/mL), (SDS) & $0.16 \pm 1.57$ \\
During GH treatment & \\
Mean GH dose 2 yr (mg/wk/kg) & $0.27 \pm 0.05$ \\
$\Delta I G F-1 S D S$ & $1.45 \pm 2.20$
\end{tabular}

Values are presented as mean \pm standard deviation unless otherwise indicated.

SGA, small for gestational age; GH, growth hormone; BA, bone age; CA, chronologic age; BMI, body mass index; IGF-1, insulinlike growth hormone factor 1 ; SDS, standard deviation score.

\section{Clinical and laboratory changes during GH treatment for 2 years}

After the first year of GH treatment, the mean height increases were $9.43 \pm 1.40 \mathrm{~cm}$ and after the next year of $\mathrm{GH}$ treatment, they were $7.63 \pm 1.16 \mathrm{~cm}(P<0.05)$. The total height change was $17.06 \pm 1.84 \mathrm{~cm}$ over the 2 -year $\mathrm{GH}$ therapy regimen. Weight was gradually increased and IGF-1 levels $(P<0.05)$ also increased after the first year of GH treatment with a smaller increase after the following treatment year. The mean height SDS change value ( $\triangle \mathrm{Ht}$ SDS) increased $0.84 \pm 0.27 \mathrm{~cm}$ after the first year of GH therapy $(P<0.05)$ and $0.42 \pm 0.19 \mathrm{~cm}$ after the following year $(P<0.05)$. During the 2 -year $\mathrm{GH}$ treatment, the total height SDS increased $1.26 \pm 0.33 \mathrm{~cm}$. Additionally, the weight SDS value increase was significantly correlated with the 2 -year $\mathrm{GH}$ treatment $(P<0.05)$ (Figs. 1, 2). As each height and weight value increased, the BMI SDS value was not significantly altered

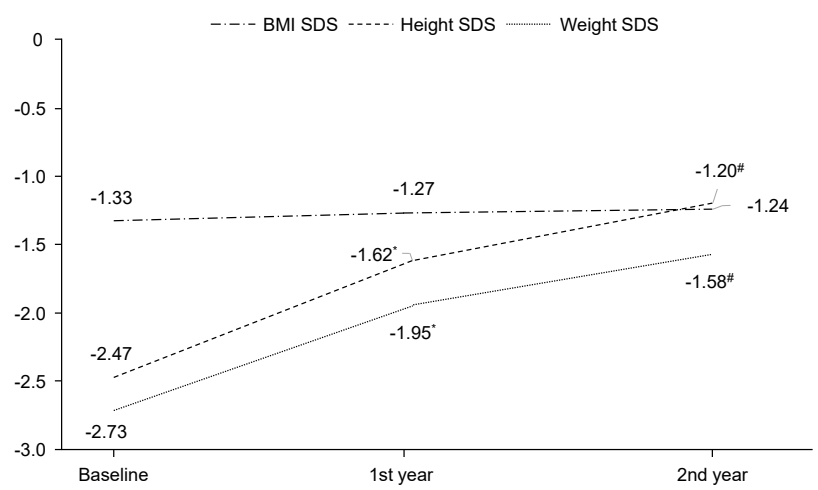

Fig. 2. Clinical and laboratory SDS change values during growth hormone treatment for 2 years. ${ }^{*} P<0.05$, significant treatment difference for to first year compared baseline. ${ }^{*} P<0.05$, significant treatment difference for second year compared to baseline.
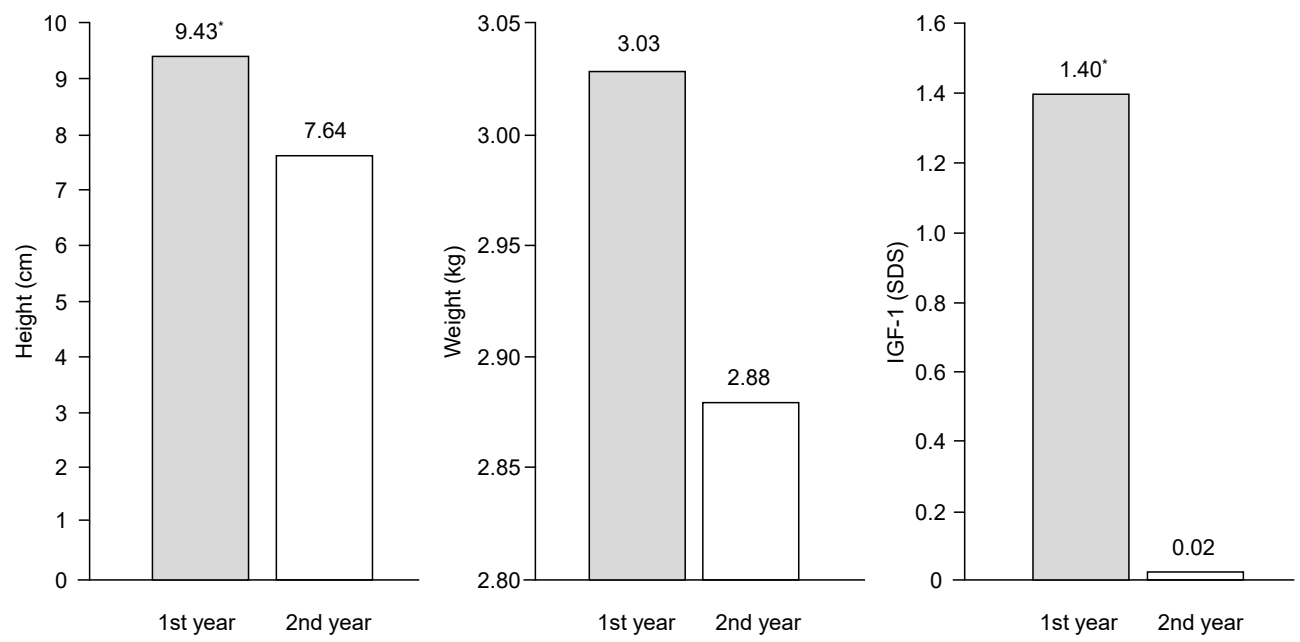

Fig. 1. The change in velocity of clinical and laboratory values during growth hormone treatment for 2 years. ${ }^{*} P<0.05$, significant treatment difference for first year compared to second year. SDS, standard deviation score. 
between initiation and after the 2-year intervention.

\section{Correlation analysis and multiple linear regression analysis between $\mathrm{GH}$ treatment response ( $\Delta \mathrm{Ht} \mathrm{SDS}$ ) and clinical factors}

Significant correlation factors of the GH treatment response $(\triangle \mathrm{Ht}$ SDS) for SGA children who failed to undergo catch-up growth were $\mathrm{CA}(P=0.047)$ and $\mathrm{BA}(P=0.049)$ at the initiation of $\mathrm{GH}$ treatment. Although we regarded variable predicting factors including GA, birth weight, and initial SDS parameters (height, weight, BMI, and IGF-1), there were no significant correlations other than those for BA and CA at the initiation of GH therapy. The BA or CA and the mean height SDS change had a negative significant correlation (Table 2). The mean GH dose $(P=0.028)$ and change value in IGF-1 SDS $(P=0.012)$ had a significantly positive correlation with response to $\mathrm{GH}$ treatment $(\triangle \mathrm{Ht} \mathrm{SDS})$ over the 2 years (Table 2). In multiple regression analysis for influencing factors of GH treatment response, only IGF-1 SDS change value ( $\beta=0.047, P=0.041)$ was significantly associated with response to $\mathrm{GH}$ treatment (Table 3).

\section{Discussion}

According to our analysis, GH therapy has a significant effect in SGA children with short stature who do not undergo catchup growth. Particularly, height SDS in the first year of GH treatment showed significant growth compared with the second year. Additionally, both CA and BA were significant correlation factors of GH treatment response in SGA children. We predict better growth responses with early GH therapy. As the IGF1 SDS value is positively correlated with $\Delta \mathrm{Ht}$ SDS, monitoring

Table 2. The analysis of correlation between growth hormone treatment response ( $\Delta \mathrm{Ht}$ SDS) and clinical factors

\begin{tabular}{lcc}
\hline Category & $R$ value & $P$-value \\
\hline At birth & & \\
Gestational age & -0.037 & 0.836 \\
Birth weight & 0.092 & 0.605 \\
At initiation of GH & & \\
CA & -0.343 & $0.047^{*}$ \\
BA & -0.341 & $0.049^{*}$ \\
BA/CA & -0.920 & 0.605 \\
Height SDS & 0.006 & 0.973 \\
Weight SDS & 0.295 & 0.090 \\
BMI SDS & 0.290 & 0.090 \\
IGF-1 SDS & -0.163 & 0.357 \\
During GH treatment & & \\
Mean GH dose 2 yr & 0.377 & $0.028^{*}$ \\
$\Delta$ IGF-1 SDS 2 yr & 0.425 & $0.012^{*}$ \\
\hline SDS, standard deviation sCore; GH, growth hormone; CA,
\end{tabular}

SDS, standard deviation score; GH, growth hormone; CA, chronologic age; BA, bone age; BMI, body mass index; IGF-1, insulin-like growth hormone factor 1; SDS, standard deviation score.

${ }^{*} P<0.05$, significant difference.
IGF-1 levels is important to GH treatment outcomes for a 2-year follow-up in SGA prepubertal children.

The mean GH treatment initiation age was $5.54 \pm 1.73$ years in our study, which is similar to another Korean GH therapy study. In a recent multicenter study, at the beginning of GH treatment, the median age of GH therapy in Korean SGA children was 6.66 years in a 5-year analysis. ${ }^{20)}$ Due to Korean medical insurance covering short stature SGA children after 4 years of age, the majority of Korean study results showed that the mean initial age was over 4 years. Another previous study also showed that the $\mathrm{CA}$ at the beginning of treatment ranged from 7.9 to 10.7 years. ${ }^{9)}$ However, there have been a select number of studies that have analyzed the GH treatment response of SGA children who were younger than 4 years of age. Boguszewski et al. ${ }^{21)}$ reported that GH treatment significantly increased growth velocity in 2to 4 -year-old children over 3 years.

In our study, the first GH treatment year exhibited greater improvement in growth velocity. The mean growth velocity was sustained above $7 \mathrm{~cm}$ for the initial year until the second year and then down to $5.3-5.74 \mathrm{~cm}$ gradually over 4 years in a Korean study. ${ }^{20)}$ Another study has shown that the height velocity for short stature SGA children was observed at $8.3 \mathrm{~cm}$ per year, in addition to significant improvements in height SDS over the first treatment year. ${ }^{22}$ In most studies, a significant increase in growth velocity has been shown, and it was more marked in the first year of $\mathrm{GH}$ treatment. ${ }^{23)}$ In our study, height velocity in the first year was $9.43 \pm 1.40 \mathrm{~cm}$, and in the second year it was $7.63 \pm 1.16 \mathrm{~cm}$. The height SDS increased $0.84 \pm 0.27$ in the first year and $0.42 \pm 0.19$ in the second year. Dahlgren et $\mathrm{al}^{24)}$ reported a height SDS increase of 1.3 from the start of GH therapy to the final height outcome in SGA children.

In an attempt to analyze the factors influencing $\mathrm{GH}$ response, several studies have revealed that specific patient factors including birth weight, sex, and gestation age may have a significant correlation with GH treatment response. On the other hand, some studies have reported mixed results on the factors that influence GH therapy in SGA children. Meazza et al. ${ }^{25)}$ showed that birth size and birth weight are important factors affecting response to GH therapy during the first 5 years of treatment. However, according to de Kort et al., ${ }^{26)}$ there was no difference between term and preterm SGA infants in growth response to GH therapy. In our study, response was not

Table 3. Multiple regression analysis for associated factors of GH treatment response ( $\Delta \mathrm{Ht}$ SDS)

\begin{tabular}{lcccc}
\hline Category & $\begin{array}{c}\text { Unstandardized } \\
\text { coefficient B }\end{array}$ & SE & $\beta$ & $P$-value \\
\hline CA & -0.060 & 0.089 & -0.032 & 0.947 \\
BA & -0.035 & 0.089 & -0.201 & 0.669 \\
Mean GH dose 2 yr & 0.615 & 0.362 & 0.276 & 0.100 \\
AIGF-1 SDS 2 yr & 0.047 & 0.023 & 0.331 & $0.045^{*}$ \\
\hline
\end{tabular}

GH, growth hormone; SDS, standard deviation score; SE, standard error; CA, chronologic age; BA, bone age; IGF-1, insulin-like growth hormone factor 1 .

${ }^{*} P<0.05$, significant difference. 
related to birth weight or gestational age. Although we do not completely understand these differing results, they may be due to the varied study population size.

Additional studies have shown significant growth outcomes related to beginning $\mathrm{GH}$ treatment for a longer duration and at an earlier age in prepubertal children. Lower baseline height SDS and younger age at baseline were significant factors that affect improved height SDS after 4 years of GH therapy. Earlier GH therapy initiation is related to improved response in growth increases. Despite some height loss during puberty, younger age at GH therapy initiation results in improved adult height results. ${ }^{27,28)}$ Ranke et al. investigated predicting factors in SGA individuals and stated that weight SDS at the start and GH dose had a positive relation and the age at the beginning of therapy had a negative relation. In another Swedish study, a regression model for adult height SDS showed that height SDS at the initiation of GH therapy is positively related and age at the initiation is negatively related. ${ }^{24,29)}$ Moreover, de Ridder et al. ${ }^{30)}$ demonstrated that height SDS at the beginning of treatment, target height SDS, GH dose, and CA-BA at the beginning of treatment all have a positive correlation with treatment outcomes, and IGF-binding protein 3 (IGFBP-3) SDS at the beginning of treatment was a negative significant determinant factor. Additionally, IGF-1 level is demonstrated to have an inverse correlation in childhood with growth factors independently. ${ }^{31)}$ Although some factors were not significant, our study results were similar to those of other previous studies. Target SDS and IGFBP-3 levels were not included in our study; therefore, further investigation of these factors will be required.

Previous studies have demonstrated that GH dose was one of the most important predictors of growth response. In these studies, the GH dose positively correlated with height SDS change. However, Van Pareren et al. ${ }^{10)}$ reported that even though each patient group underwent treatment with a daily dose of 33 or $66 \mu \mathrm{g} / \mathrm{kg}$, there was no difference in adult height. Whether higher doses contribute to an increased growth response is still uncertain, as some investigators found that higher $\mathrm{GH}$ dose has a positive influence on the growth response curve, but others demonstrated similar responses with a lower dose. In recent years, the effect of a larger dosage on IGF-1 production has been of interest. Increased IGF-1 levels are positively associated with height increase in prepubertal children ${ }^{32}$. Kappelgaard et al. ${ }^{33)}$ showed a positive relationship between IGF-1 SDS level and height SDS increase, suggesting it is an important factor for monitoring a patient's GH therapy response. In the present study, IGF-1 SDS change and mean GH dose had a significantly positive correlation with height SDS increases. Although mean GH dose was positively correlated with height SDS increase, the starting GH dose in all children was approximately $0.33 \mathrm{mg} /$ $\mathrm{kg} /$ week and adjusted within the similar range of initial dose according to growth velocity. Because $\mathrm{GH}$ dose differences were not associated with a meaningful difference in treatment effect, it is difficult to conclude that there is a correlation between GH dose and GH treatment effect. IGF-1 SDS increase was associated with increased growth gain in GH treatment in SGA prepubertal children with short stature. Moreover, in multiple regression analysis, IGF-1 SDS change was a significant factor in GH treatment effect. IGF-1 level monitoring may be necessary to evaluate $\mathrm{GH}$ response.

Since this study was a retrospective single-center study including a limited number of patients, larger prospective studies are required. Appropriate sample size and power should be considered. Due to the limited patient population, we selected only a few variable factors and, therefore, could not consider all associated factors. Moreover, Rapaport et al. ${ }^{34)}$ showed that GHsufficient SGA children exhibited better improvement in height SDS than those with idiopathic GH deficiency. This result demonstrates, depending on GH status, variability in accordance with GH treatment among SGA patients. However, another study recommend that because the GH stimulation test appears to be of little value in determining the response to GH therapy, $\mathrm{GH}$ stimulation testing is not required to identify candidates for GH therapy among children born with SGA who fail to achieve catch-up growth. ${ }^{35)}$ As evaluating GH stimulation test results was not our study aim, we could not compare sufficient and/or deficient GH status among our patients. Furthermore, our study could not investigate adverse events including insulin resistance, hyperglycemia, and thyroid function during treatment followup; therefore, further analysis is required for these potential side effects.

In conclusion, this study demonstrated that GH treatment is effective for prepubertal children without catch-up growth who are born SGA. Additionally, we predict better growth outcomes with earlier initiation of GH therapy. The strength of our study is that the overall influencing factors of the GH treatment period were analyzed rather than the respective evaluation of $\mathrm{GH}$ treatment in response to birth data, initiation, and treatment duration. Moreover, we determined that IGF-1 monitoring can predict effective height growth even without a high dose of $\mathrm{GH}$ and that IGF-1 level monitoring is important in GH treatment follow-up for short stature SGA prepubertal children. As GH treatment in SGA children diagnosed with short stature is increasingly applied, large-scale and long-term studies including final adult heights are needed to develop appropriate $\mathrm{GH}$ treatment strategies for short stature SGA children who without catch-up growth in Korea.

\section{Ethical statement}

This study was conducted in accordance with the principles expressed in the Declaration of Helsinki and applicable regulations. The Institutional Review Board of the medical center examined and approved the study protocol (AJIRBMED-MDB-19-577).

\section{Conflict of interest}

No potential conflict of interest relevant to this article was reported. 


\section{References}

1. Lee PA, Chernausek SD, Hokken-Koelega AC, Czernichow P; International Small for Gestational Age Advisory Board. International Small for Gestational Age Advisory Board consensus development conference statement: management of short children born small for gestational age, April 24-October 1, 2001. Pediatrics 2003;111(6 Pt 1):1253-61.

2. Karlberg J, Albertsson-Wikland K. Growth in full-term small-for-gestational-age infants: from birth to final height. Pediatr Res 1995;38:733-9.

3. Labarta JI, Ruiz JA, Molina I, De Arriba A, Mayayo E, Longás AF. Growth and growth hormone treatment in short stature children born small for gestational age. Pediatr Endocrinol Rev 2009;6 Suppl 3:350-7.

4. Pierrat V, Marchand-Martin L, Guemas I, Matis J, Burguet A, Picaud JC, et al. Height at 2 and 5 years of age in children born very preterm: the EPIPAGE study. Arch Dis Child Fetal Neonatal Ed 2011;96:F348-54.

5. Battaglia FC, Lubchenco LO. A practical classification of newborn infants by weight and gestational age. J Pediatr 1967;71:159-63.

6. Bozzola E, Meazza C, Arvigo M, Travaglino P, Pagani S, Stronati M, et al. Role of adiponectin and leptin on body development in infants during the first year of life. Ital J Pediatr 2010;36:26.

7. Cianfarani S, Ladaki C, Geremia C. Hormonal regulation of postnatal growth in children born small for gestational age. Horm Res 2006;65 Suppl 3:70-4.

8. Hokken-Koelega AC, De Ridder MA, Lemmen RJ, Den Hartog H, De Muinck Keizer-Schrama SM, Drop SL. Children born small for gestational age: do they catch up? Pediatr Res 1995;38:267-71.

9. Maiorana A, Cianfarani S. Impact of growth hormone therapy on adult height of children born small for gestational age. Pediatrics 2009;124:e519-31.

10. Van Pareren Y, Mulder P, Houdijk M, Jansen M, Reeser M, Hokken-Koelega A. Adult height after long-term, continuous growth hormone $(\mathrm{GH})$ treatment in short children born small for gestational age: results of a randomized, double-blind, dose-response GH trial. J Clin Endocrinol Metab 2003;88:3584-90.

11. van der Steen M, Hokken-Koelega AC. Growth and metabolism in children born small for gestational age. Endocrinol Metab Clin North Am 2016;45:283-94.

12. Lem AJ, van der Kaay DC, de Ridder MA, Bakker-van Waarde WM, van der Hulst FJ, Mulder JC, et al. Adult height in short children born SGA treated with growth hormone and gonadotropin releasing hormone analog: results of a randomized, dose-response GH trial. J Clin Endocrinol Metab 2012;97:4096-105.

13. Rapaport R. Growth and growth hormone in children born small for gestational age. Growth Horm IGF Res 2004;14
Suppl A:S3-6.

14. Carel JC, Chatelain P, Rochiccioli P, Chaussain JL. Improvement in adult height after growth hormone treatment in adolescents with short stature born small for gestational age: results of a randomized controlled study. J Clin Endocrinol Metab 2003;88:1587-93.

15. Hwang IT. Efficacy and safety of growth hormone treatment for children born small for gestational age. Korean J Pediatr 2014;57:379-83.

16. Greulich WW, Pyle SI. Radiographic atlas of skeletal development of the hand and wrist. 2nd ed. Stanford: Stanford University Press, 1959.

17. Hyun SE, Lee BC, Suh BK, Chung SC, Ko CW, Kim HS, et al. Reference values for serum levels of insulin-like growth factor-I and insulin-like growth factor binding protein-3 in Korean children and adolescents. Clin Biochem 2012;45:16-21.

18. Kim JH, Yun S, Hwang SS, Shim JO, Chae HW, Lee YJ, et al. The 2017 Korean National Growth Charts for children and adolescents: development, improvement, and prospects. Korean J Pediatr 2018;61:135-49.

19. Tanner JM, Whitehouse RH. Clinical longitudinal standards for height, weight, height velocity, weight velocity, and stages of puberty. Arch Dis Child 1976;51:170-9.

20. Rhie YJ, Yoo JH, Choi JH, Chae HW, Kim JH, Chung S, et al. Long-term safety and effectiveness of growth hormone therapy in Korean children with growth disorders: 5-year results of LG Growth Study. PLoS One 2019;14:e216927.

21. Boguszewski MC, Lindberg A, Wollmann HA. Three-year growth response to growth hormone treatment in very young children born small for gestational age-data from KIGS. J Clin Endocrinol Metab 2014;99:2683-8.

22. Boguszewski MC, Karlsson H, Wilton P. Short children born prematurely: data from KIGS. Horm Res Paediatr 2011;76 Suppl 1:39-41.

23. Aurensanz Clemente E, Samper Villagrasa P, Ayerza Casas A, Ruiz Frontera P, Bueno Lozano O, Moreno Aznar LA, et al. Modificaciones en variables antropométricas, analíticas de riesgo metabólico y composición corporal en pequeños para la edad gestacional en tratamiento con hormona de crecimiento Effects of growth hormone treatment on anthropometrics, metabolic risk, and body composition variables in small for gestational age patients. An Pediatr (Barc) 2017;86:240-8.

24. Dahlgren J, Wikland KA; Swedish Study Group for Growth Hormone Treatment. Final height in short children born small for gestational age treated with growth hormone. Pediatr Res 2005;57:216-22.

25. Meazza C, Pagani S, Pietra B, Tinelli C, Calcaterra V, Bozzola $\mathrm{E}$, et al. Different long-term response to growth hormone therapy in small- versus appropriate-for-gestational-age children with growth hormone deficiency. Horm Res Paediatr 2013;79:214-9.

26. de Kort SW, Willemsen RH, van der Kaay DC, Duivenvoorden HJ, Hokken-Koelega AC. Does preterm birth influence 
the response to growth hormone treatment in short, small for gestational age children? Clin Endocrinol (Oxf) 2009;70:582-7.

27. Ranke MB, Lindberg A; KIGS International Board. Height at start, first-year growth response and cause of shortness at birth are major determinants of adult height outcomes of short children born small for gestational age and SilverRussell syndrome treated with growth hormone: analysis of data from KIGS. Horm Res Paediatr 2010;74:259-66.

28. Renes JS, Willemsen RH, Mulder JC, Bakker-van Waarde WM, Rotteveel J, Oostdijk W, et al. New insights into factors influencing adult height in short SGA children: results of a large multicentre growth hormone trial. Clin Endocrinol (Oxf) 2015;82:854-61.

29. Ranke MB, Lindberg A, Cowell CT, Wikland KA, Reiter EO, Wilton $\mathrm{P}$, et al. Prediction of response to growth hormone treatment in short children born small for gestational age: analysis of data from KIGS (Pharmacia International Growth Database). J Clin Endocrinol Metab 2003;88:12531.

30. de Ridder MA, Stijnen T, Hokken-Koelega AC. Prediction model for adult height of small for gestational age children at the start of growth hormone treatment. J Clin Endocrinol
Metab 2008;93:477-83.

31. Fall CH, Pandit AN, Law CM, Yajnik CS, Clark PM, Breier $\mathrm{B}$, et al. Size at birth and plasma insulin-like growth factor-1 concentrations. Arch Dis Child 1995;73:287-93.

32. Cohen P, Rogol AD, Howard CP, Bright GM, Kappelgaard $\mathrm{AM}$, Rosenfeld RG, et al. Insulin growth factor-based dosing of growth hormone therapy in children: a randomized, controlled study. J Clin Endocrinol Metab 2007;92:2480-6.

33. Kappelgaard AM, Kiyomi F, Horikawa R, Yokoya S, Tanaka T. The impact of long-term growth hormone treatment on metabolic parameters in Japanese patients with short stature born small for gestational age. Horm Res Paediatr 2014;81:272-9.

34. Rapaport R, Lee P, Ross J, Saenger P, Ostrow V, Piccoli G. Growth hormone therapy in children born small for gestational age: results from the ANSWER program. Endocr Connect 2018;7:1096-104.

35. Azcona C, Albanese A, Bareille P, Stanhope R. Growth hormone treatment in growth hormone-sufficient and -insufficient children with intrauterine growth retardation/ Russell-Silver syndrome. Horm Res 1998;50:22-7. 